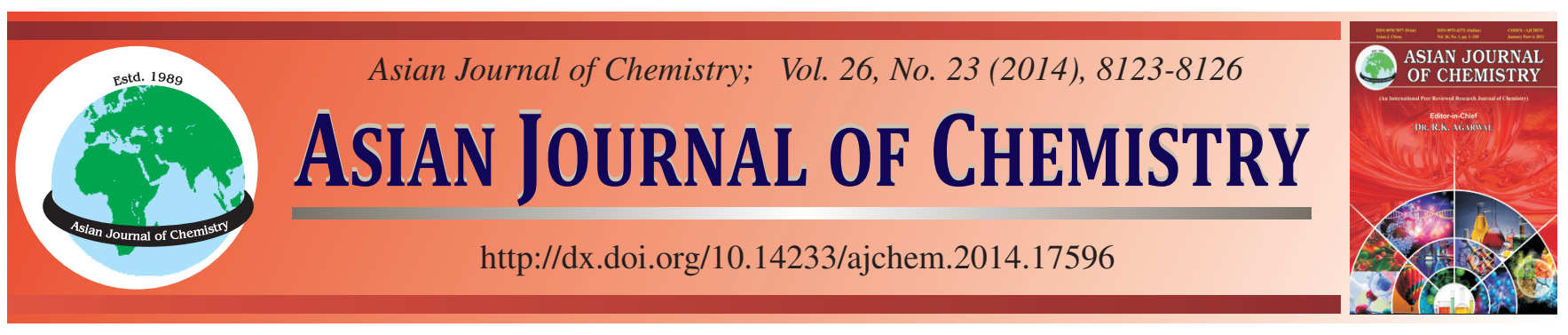

\title{
Determination of Monomer Phenols in Cane Juice by Reversed-Phase High-Performance Liquid Chromatography with UV Detection
}

\author{
Xinquan Liang ${ }^{1, *}$, Xianhui Liang ${ }^{1}$, Huihuan $\mathrm{He}^{2}, \mathrm{Jidong}_{\mathrm{Li}}{ }^{1}$ and Denguun Lu${ }^{1}$
}

${ }^{1}$ Light Industry and Food Engineering Institute, Guangxi University, 100 Daxue Road, Nanning, Guangxi 530004, P.R. China ${ }^{2}$ Guangxi Vocational \& Technical Institute of Industry, 37 Xiuling Road, Nanning, Guangxi 530004, P.R. China

*Corresponding author: Fax: +86 771 3231590; Tel: +86 771 3237329; E-mail: liuan6126@126.com

\begin{abstract}
A reversed phase high-performance liquid chromatography method was used in simultaneous determination of 6 monomer phenols (e.g., gallic acid, catechin, chlorogenic acid, caffeic acid, epicatechin and ferulic acid) in cane juice. A variable wavelength UV detector and a $\mathrm{C}_{18}$ column $(250 \mathrm{~mm} \times 4.6 \mathrm{~mm} 5 \mu \mathrm{m})$ were used. The mixture of methanol, acetic acid and water were used as the mobile phase in a gradient mode. Five monomer phenols (gallic acid, chlorogenic acid, caffeic acid, epicatechin and ferulic acid) were detected in cane juice with an average recovery ratio of 81.6-93.7\% and the relative standard deviations (RSD) were less than $5 \%$. This method is a convenient, rapid and accurate way for simultaneous determination of monomer phenols in cane juice.
\end{abstract}

Keywords: RP-HPLC, Cane juice, Phenols.

\section{INTRODUCTION}

The process of refine sugar from sugarcane juice would lead to the formation of pigments and decrease the quality of white granulated sugar (WGS), due to the high quantity of monomer phenols remaining in cane juice ${ }^{1}$. The ways of phenols leading to pigments contains enzymatic browning, oxidation, aggregating, complex reactions between ferric irons and reactions between proteins and amino acids and so on ${ }^{2}$. Previous reports indicated that polyphenol oxidase (PPO) from tissues of sugarcane would oxidize phenols and lead to brown in cane juice. Tannins are condensate of catechins in cane juice that would react with ferric irons under oxidase catalysis and result in sap green of cane juice. Besides, compounds with similar phenyl salicylate structure such as catechin, epicatechin, anthocyanin derivatives. Gallic acid and caffeic acid were correlated with the pigment of the tissues and ferulic acid was the key factor that leads to the pigment of sugar during storage ${ }^{3}$. Thus, a further research to discover the alterations of phenols in cane juice would be helpful to increase the quality of sugar by decreasing the color value.

High-performance liquid chromatography (HPLC) is one of the most used and efficiency separation technology in the lab and exhibited a high resolution ratio, a fast analysis speed, a good repeatability and a high precision on quantitative research. Phenols from sugar cane juice were isolated and identified using reversed phase HPLC with diode array detector and tricin, digicitrine, aglucon, caffeic acid, erucic acid and hydroxy-cinnamic acid from sugar cane juice were detected ${ }^{4}$. Similar research also reported qualitative and quantitative analysis of flavones (including apigenin, luteolin and tricin derivatives) and phenylpropanoid compounds (including caffeic acid, chlorogenic acid and coumaric acid) in different variety of sugarcane, juice, syrup and molasses. Although various methods could isolate and identify phenols ${ }^{5,6}$, qualitative and quantitative analysis of phenols from sugarcane juice using reversed phase HPLC with ultraviolet detector (RPHPLC-UV) has not been reported to date. In the present study, we take gallic acid, catechin, chlorogenic acid, caffeic acid, epicatechin and ferulic acid as the object of the research and constructed a rapid method to accurate qualitative and quantitative analysis of phenols from sugarcane juice using RP-HPLC-UV ${ }^{7}$. The method would be helpful to the sugarcane juice decoloration process in the refining of sugars.

\section{EXPERIMENTAL}

Preparation of samples: The cane mixed juice used in this study was produced in Mingyang sugar refinery (Nanning, Guangxi, China). Sugarcane juice samples (10 mL, pH 7) were vibrated with $10 \mathrm{~mL}$ of ethyl acetate for $1.5 \mathrm{~min}$ at room temperature and left for $15 \mathrm{~min}$. The surface layer was extracted and the under layer was separated and adjust $\mathrm{pH}$ to 2.5 with $\mathrm{HCl}$, then followed with an extraction with $10 \mathrm{~mL}$ of ethyl acetate was filtered, mixed with $2 \mathrm{~mL}$ water, reduced in volume to 
$2 \mathrm{~mL}$ on a rotary evaporator and was purified by solid-phase extraction (SPE) using Oasis HLB cartridges (3 cc, 60 mg; 30 $\mu \mathrm{m}$ particle size; Waters, Milford, MA, USA) pre-conditioned with $1 \mathrm{~mL}$ of methanol and $1 \mathrm{~mL}$ of water. The interfering compounds were eluted with $3 \mathrm{~mL}$ of water, whilst the flavonoids were obtained by elution with $3 \mathrm{~mL}$ of methanol. Purified flavonoid extracts were filtered through $0.5 \mu \mathrm{m}$ fluorpore membranes (Millipore) prior to injection into the HPLC system, as previously reported ${ }^{8}$.

Reagents and standards: The standards used for analysis of phenolic compounds were gallic acid, catechin, chlorogenic acid, caffeic acid, epicatechin and ferulic acid. All the standards were purchased from Sigma Aldrich (Sigma-Aldrich, Shanghai, China). The solvents for chromatography were of HPLC analytical grade: menthol (Sigma), acetic acid (Sigma), ultrapure water obtained from a Milli-Q system and ethyl acetate (Sigma) were used.

Chromatographic conditions: Analyses of phenolic compounds were performed on a reversed phase HPLC. The apparatus was a Waters 600E pump system controller connected to a LC spectrophotometer (Waters) set at $280 \mathrm{~nm}$ and separation was performed using a preparative Waters hypersil $\mathrm{BDS} \mathrm{C}_{18}$ column $(250 \mathrm{~mm} \times 4.6 \mathrm{~mm}, 5 \mu \mathrm{m})$. The mobile phase was menthol as eluent A and water/ethyl acetate (1000:5, v/v) as eluent $\mathrm{B}$. The samples were eluted according to the following gradient: 0 to $30 \mathrm{~min}(0-30 \% \mathrm{~A}) ; 30$ to $40 \mathrm{~min}(30 \% \mathrm{~A})$; $40-$ $55 \mathrm{~min}(30-90 \% \mathrm{~A}) ; 55$ to $60 \mathrm{~min}(90-10 \% \mathrm{~A})$. The flow rate was $1 \mathrm{~mL} / \mathrm{min}$ and two injections of $10 \mathrm{~mL}$ each were performed. Each fraction was manually collected and lyophilized. Purity was checked by mass spectrometry and analytical RPHPLC.

Preparation of standard and sample solutions: Stock solutions containing $1000 \mathrm{mg} / \mathrm{L}$ of each of the phenol standards were prepared in $50 \%$ ethyl alcohol. The external standard method was employed for the quantification of the compounds. Analytical curves were constructed through dilution of the intermediate solution containing a mixture of all the standards that obtained by dilution of the stock solutions. Each sample was injected in triplicate.

Samples and standards were filtered through a polyethylene membrane and injected directly into the chromatograph system. Injections of samples were performed in duplicate and the identities of the analyses were confirmed by comparison of the retention times and peak profiles of the samples with those of the standards.

\section{RESULTS AND DISCUSSION}

Optimal of chromatographic conditions in the separation of monomer phenols using RP-HPLC-UV: To determine the optimal absorption wavelength of mono-phenols in sugarcane juice, the absorption spectra between 260 to 360 $\mathrm{nm}$ was scanned using ultraviolet spectrophotometer and the results indicated that all samples under wavelength $280 \mathrm{~nm}$ exhibited a better absorption value (Fig. 1). Similar results also reported in previous research, which showed that $280 \mathrm{~nm}$ was the proper absorption wavelength to phenols 9 . Thus, a wavelength of $280 \mathrm{~nm}$ was chosen in the following research to identify mono-phenols using RP-HPLC.

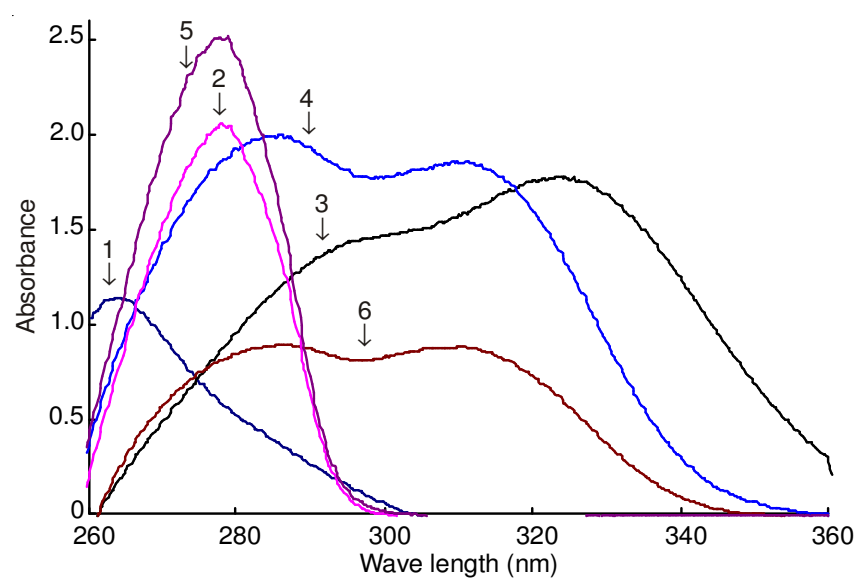

Fig. 1. UV spectra of six monomer phenols; 1. Gallic acid; 2, Catechin; 3, Chlorogenic acid; 4, Caffeic acid; 5, Epicatechin; 6, Ferulic acid

To determine the optimal elution conditions of monomer phenols in sugarcane juice using RP-HPLC, the mixed six samples $(10 \mu \mathrm{L})$ were injected into a reversed $\mathrm{C}_{18}$ column and then were eluted with variable mobile phase. The mobile phase composed of solution A and B in a ratio of 4:6, 3.5:6.5, 3:7, $2: 8$ and $1.5: 8.5$. The RP-HPLC chromatogram indicated that a 3.5:6.5 ratio between solution A and B could separate all the samples, whereas, gallic acid (peak 1, $4.1 \mathrm{~min}$ ) is near to catechin (peak 2, $4.2 \mathrm{~min}$ ) and could not be totally separated (Fig. 2). The separation efficiency was improved when a 1.5:8.5 ratio between solution $A$ and $B$ was conducted and peak 1 and peak 2 was thoroughly separated. However, the retention time of the latter compounds was prolonged to even $40 \mathrm{~min}$ and the peak spacing was relatively large (data not shown). Thus, a constant elution method was not proper for the separation of mono-phenols.

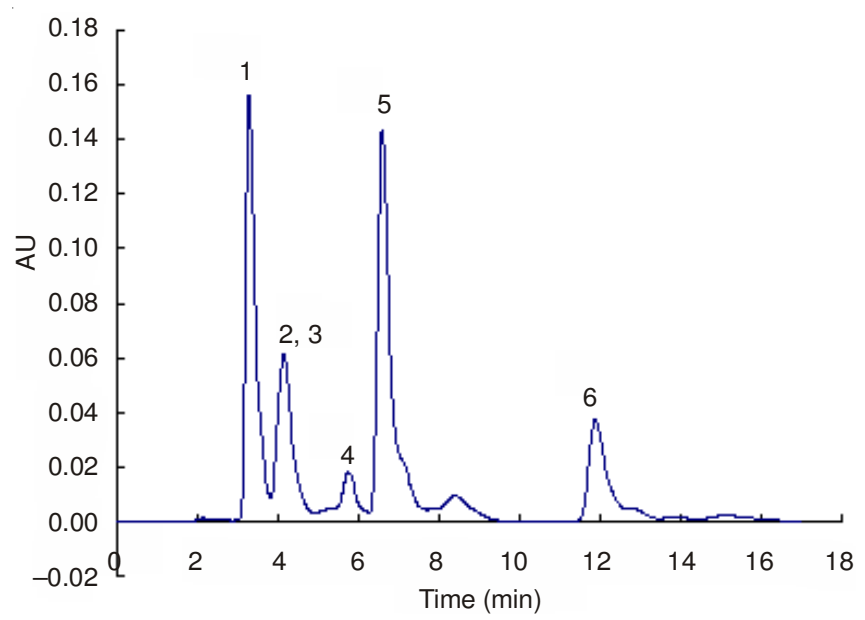

Fig. 2. Chromatogram of 6 kinds of monomer phenols under the isocratic elution; 1. Gallic acid; 2, Catechin; 3, Chlorogenic acid; 4, Caffeic acid; 5, Epicatechin; 6, Ferulic acid

As an isocratic elution manner showed an unfavorable separation result, gradient elution was considered in this study. The samples were eluted according to the following gradient: 0 to $30 \mathrm{~min}(0-30 \% \mathrm{~A}) ; 30$ to $40 \mathrm{~min}(30 \% \mathrm{~A})$; 40-55 $\mathrm{min}$ (30-90\% A); 55 to $60 \mathrm{~min}(90-10 \% \mathrm{~A})$. The flow rate was 1 $\mathrm{mL} / \mathrm{min}$ and two injections of $10 \mathrm{~mL}$ each were performed. The gradient elution results showed that all the six monomer 


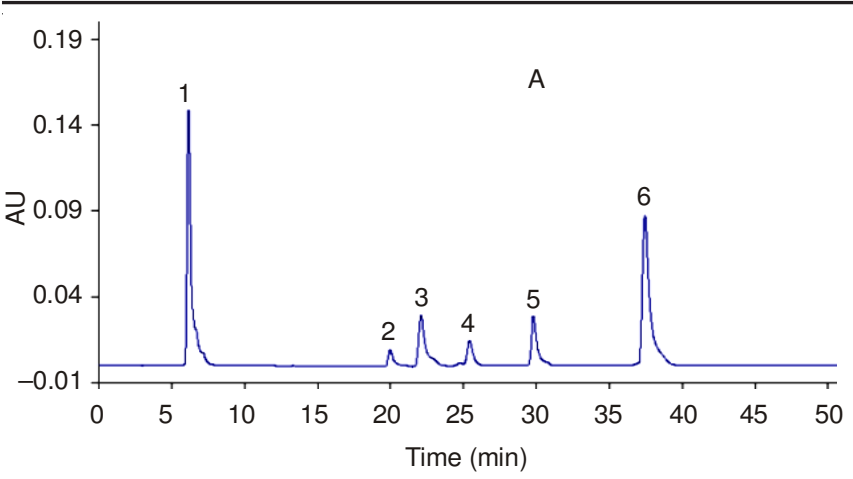

Fig. 3. Chromatogram of 6 kinds of mono-phenols under the gradient elution; 1, Gallic acid; 2, Catechin; 3, Chlorogenic acid; 4, Caffeic acid; 5, Epicatechin; 6, Ferulic acid

phenols were separated efficiently (Fig. 3). Thus, gradient elution manner was chosen for qualitative analysis of monomer phenols in sugarcane juice.

To determine the optimal mobile phase in separating of monomer phenols in sugarcane juice using RP-HPLC, mobile phase with and without acetic acid was chosen in the present study, as shown in Fig. 4.

The chromatogram exhibited streaking when mobile phase contained no acetic acid, especially in the chromatographic peak of gallic acid, chlorogenic acid and caffeic acid (Fig. 4a).
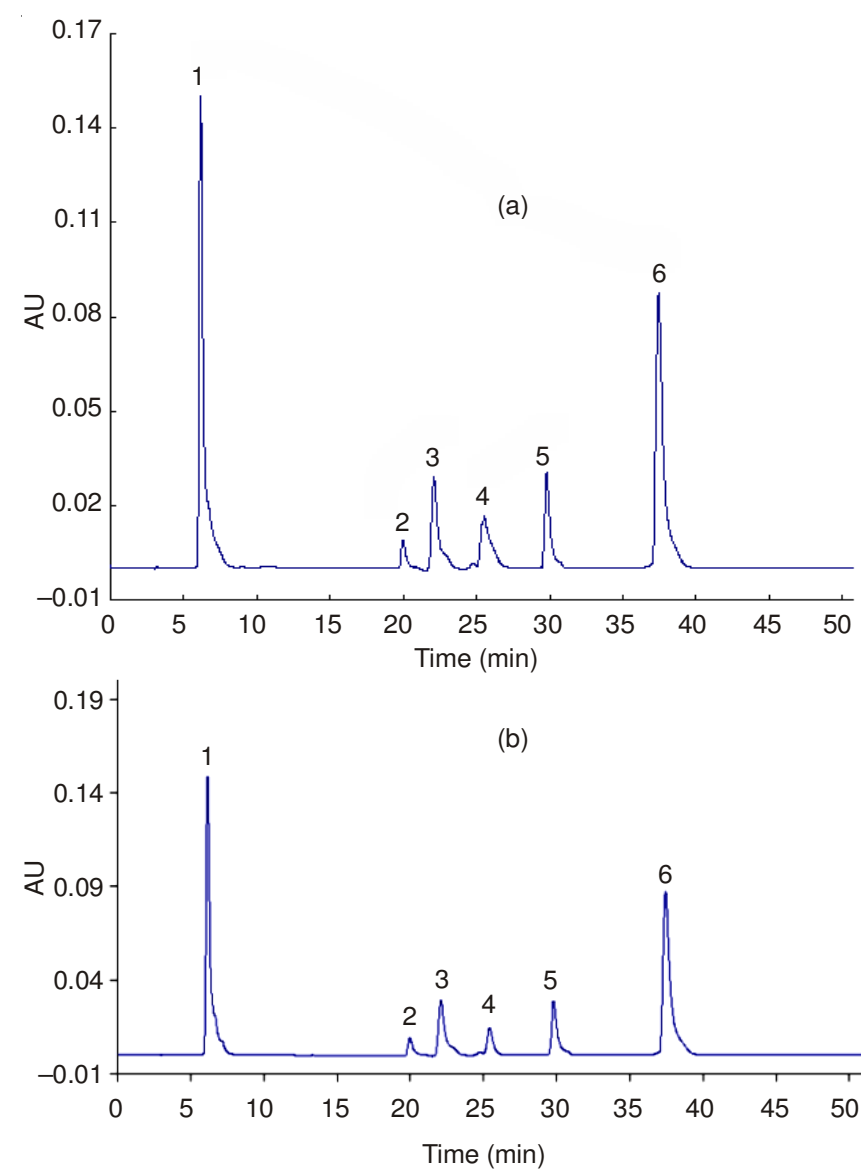

Fig. 4. Chromatogram of standard substance under different mobile phase (a) $\mathrm{CH}_{3} \mathrm{OH}$ without $\mathrm{CH}_{3} \mathrm{COOH} / \mathrm{H}_{2} \mathrm{O}$ (b) $\mathrm{CH}_{3} \mathrm{OH}$ with $0.5 \%$ $\mathrm{CH}_{3} \mathrm{COOH} / \mathrm{H}_{2} \mathrm{O} ; 1$, Gallic acid; 2, Catechin; 3, Chlorogenic acid; 4, Caffeic acid; 5, Epicatechin; 6, Ferulic acid
When different ratio of acetic acid was added into the mobile phase, reduced streaking phenomenon was detected according to the chromatogram. This may due to the ionization of phenols were restrained under acidic conditions and remain as neutral and were easier to be separated (Fig. 4a). Consideration of the application range of columns, methanol was chosen as the mobile phase $\mathrm{A}$ and $0.5 \%$ of acetic acid was chosen as the mobile phase B.

Determination of monomer phenols in sugarcane juice using RP-HPLC-UV: To evaluate the efficiency of separating monomer phenols in sugarcane juice using RP-HPLC-UV under the conditions that obtained above, samples from sugarcane juice were injected into the RP-HPLC-UV detector (Fig. 5). The results showed that five monomer phenols were detected in sugarcane juice and no visible interference factors were found in the separation of monomer phenols in sugarcane juice. Thus, the chromatographic conditions could be used in quantitative analysis of monomer phenols in sugarcane juice.

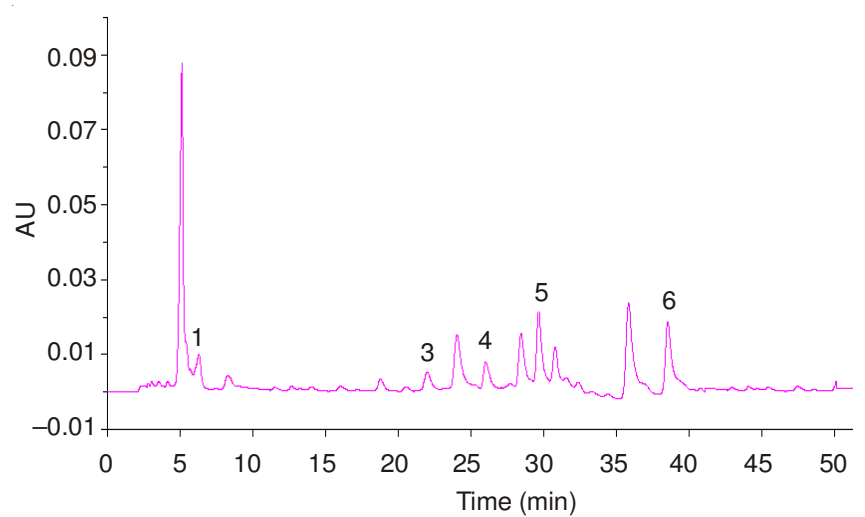

Fig. 5. Chromatograms of cane juice; 1, Gallic acid; 2, Catechin; 3, Chlorogenic acid; 4, Caffeic acid; 5, Epicatechin; 6, Ferulic acid

Evaluation of methods for determining monomer phenols in sugarcane juice using RP-HPLC-UV: To evaluate the linear relationship and detection limit of monomer phenols using RP-HPLC-UV, mixed solutions of standards at different concentrations were prepared. For each concentration of mixed solutions, $10 \mu \mathrm{L}$ of sample was injected into a RP-HPLC-UV detector and linear regression equation was calculated according to the ratio of peak area of the standard and concentration $(\mathrm{mg} / \mathrm{L})$. The linear regression equations of gallic acid, chlorogenic acid, caffeic acid, epicatechin and ferulic acid were obtained and were shown in Table-1. Also, the detection limit of the five monomer phenols were obtained under 3 folds of signal to noise ratio and the results were also shown in Table- 1 .

Table-1 showed that the correlation coefficients in linear regression equations of the five standards were all greater than 0.99, accompanied with a low detection limit. The results showed that the method was high sensitivity and was proper to quantitative analysis of monomer phenols.

To address the relative standard deviation (RSD), all the standards were storage at $4{ }^{\circ} \mathrm{C}$ for $0,2,4,12,24,36$ and $48 \mathrm{~h}$ and were then examined with RP-HPLC-UV. The peak area of each monomer phenol was shown in Table-2. The results showed that all the RSD values were within $\pm 5 \%$, which indicated that all the samples kept stable within $48 \mathrm{~h}$. 


\begin{tabular}{|c|c|c|c|c|c|c|c|c|}
\hline \multicolumn{9}{|c|}{$\begin{array}{c}\text { TABLE-2 } \\
\text { STABILITY TEST }\end{array}$} \\
\hline Sample & $0 \mathrm{~h}$ & $4 \mathrm{~h}$ & $8 \mathrm{~h}$ & $12 \mathrm{~h}$ & $24 \mathrm{~h}$ & $36 \mathrm{~h}$ & $48 \mathrm{~h}$ & $\operatorname{RSD}(\%)$ \\
\hline Glucogallic acid & 1714918 & 1639254 & 1638917 & 1693965 & 1667428 & 1647850 & 1675432 & 4.6 \\
\hline Chlorogenic acid & 1351098 & 1348593 & 1366542 & 1359834 & 1338953 & 1351859 & 1363950 & 2.0 \\
\hline Caffeic acid & 1428797 & 1427947 & 1425472 & 1432764 & 1419840 & 1428712 & 14283754 & 0.6 \\
\hline Epicatechin & 1249758 & 1252746 & 1252847 & 1265393 & 1248762 & 1259385 & 1258735 & 1.3 \\
\hline Ferulic acid & 1778535 & 1728472 & 1768424 & 1757463 & 1768452 & 1774277 & 1752457 & 1.2 \\
\hline
\end{tabular}

\begin{tabular}{lcccc}
\hline \multicolumn{5}{c}{ TABLE-1 } \\
\multicolumn{4}{c}{ REGRESSION EQUATIONS AND CORRELATION } \\
COEFFICIENTS OF THE REFERENCE SUBSTANCES \\
\hline Sample & $\begin{array}{c}\text { Linear regression } \\
\text { equation }\end{array}$ & $\begin{array}{c}\text { Linear } \\
\text { extension } \\
(\mathrm{mg} / \mathrm{L})\end{array}$ & $\begin{array}{c}\text { Correlation } \\
\text { coefficient }\end{array}$ & $\begin{array}{c}\text { Detection } \\
\text { limit } \\
(\mathrm{mg} / \mathrm{L})\end{array}$ \\
\hline Glucogallic acid & $\mathrm{Y}=18899 \mathrm{X}-135678$ & $10-300$ & 0.9911 & 1.43 \\
Chlorogenic acid & $\mathrm{Y}=10217 \mathrm{X}-99076$ & $10-300$ & 0.9995 & 1.09 \\
Caffeic acid & $\mathrm{Y}=18955 \mathrm{X}-214607$ & $10-300$ & 0.9967 & 0.83 \\
Epicatechin & $\mathrm{Y}=4213.4 \mathrm{X}-91415$ & $10-300$ & 0.9912 & 2.75 \\
Ferulic acid & $\mathrm{Y}=16356 \mathrm{X}-178462$ & $10-300$ & 0.9993 & 0.73 \\
\hline
\end{tabular}

To address the precision and the recovery of standard addition of this method, $100 \mathrm{~mL}$ of sugarcane juice were transferred into a $250 \mathrm{~mL}$ flask and then transferred into certain of gallic acid solution. According to the procedure of polyphenol extraction, samples were injected and the obtained peak area was substituted into the linear regression equation and then the concentration of gallic acid could be calculated. Companied with the average recovery of standard addition and RSD value, the precision and the recovery of standard addition of other monomer phenols were calculated (Table-3).

\begin{tabular}{|cccccc}
\multicolumn{5}{c}{ TABLE-3 } \\
\hline \multicolumn{5}{c}{ PRECISIONS AND RECOVERIES OF THE METHOD $(\mathrm{n}=3)$} \\
\hline Sample & $\begin{array}{c}\text { Original } \\
\text { value } \\
\left(\mathrm{mg} / \mathrm{kg}{ }^{\circ} \mathrm{Bx}\right)\end{array}$ & $\begin{array}{c}\text { Added value } \\
\left(\mathrm{mg} / \mathrm{kg}{ }^{\circ} \mathrm{Bx}\right)\end{array}$ & $\begin{array}{c}\text { Examined } \\
\text { value } \\
\left(\mathrm{mg} / \mathrm{kg}{ }^{\circ} \mathrm{Bx}\right)\end{array}$ & $\begin{array}{c}\text { Recovery } \\
(\%)\end{array}$ & RSD $(\%)$ \\
\hline $\begin{array}{c}\text { Glucogallic } \\
\text { acid }\end{array}$ & 14.15 & 300 & 294.36 & 93.7 & 1.72 \\
$\begin{array}{c}\text { Chlorogenic } \\
\text { acid }\end{array}$ & 5.75 & 300 & 249.49 & 81.6 & 3.35 \\
$\begin{array}{c}\text { Caffeic acid } \\
\text { Epicatechin }\end{array}$ & 6.30 & 300 & 252.08 & 82.3 & 2.11 \\
Ferulic acid & 17.38 & 300 & 269.21 & 87.2 & 3.72 \\
\hline
\end{tabular}

The results showed that all the RSD values obtained by RP-HPLC-UV were below $5 \%$ and the recovery of standard addition was 81.6 to $93.7 \%$, suggesting that this method could be used in the quantitation of monomer phenols in sugarcane juice.

\section{Conclusion}

In the present study, gallic acid, catechin, chlorogenic acid, caffeic acid, epicatechin and ferulic acid were chosen as research objects and constructed a method to qualitative and quantitate analysis of monomer phenols using RP-HPLC-UV detector, the main results obtained were described as follow: the optimal conditions of determine monomer phenols in sugarcane juice using RP-HPLC-UV were: reversed $\mathrm{C}_{18}$ column and the wavelength was $280 \mathrm{~nm}$. The mobile phases were menthol (solution A) and $0.5 \%$ of acetic acid (solution B). The samples were eluted according to the following gradient: 0 to $30 \mathrm{~min}(0-30 \% \mathrm{~A}) ; 30$ to $40 \mathrm{~min}(30 \% \mathrm{~A})$; 40-55 min (30-90\% A); 55 to $60 \mathrm{~min}(90-10 \% \mathrm{~A})$. The flow rate was $1 \mathrm{~mL} / \mathrm{min}$ and two injections of $10 \mathrm{~mL}$ each were performed. Two, gallic acid, chlorogenic acid, caffeic acid, epicatechin and ferulic acid were detected in sugarcane juice using RPHPLC-UV and no visible interferences were detected. Three, the stability and the precision examination indicated that the linear regression equation greater than 0.99 and the detection limit was very low. The RSD was blew $5 \%$ and samples kept stable within $48 \mathrm{~h}$. The recovery of standard addition was 81.6 to $93.7 \%$. The new method could fulfill the examination of gallic acid, chlorogenic acid, caffeic acid, epicatechin and ferulic acid.

\section{ACKNOWLEDGEMENTS}

This work was supported by the Key Scientific and Technological Project of Guangxi province, China (1348002-3), the Sci-Tech Support Plan Project of Guangxi province, China (10100025).

\section{REFERENCES}

1. S.K. Sharma, B. Kaushal and P. Sharma, J. Food Sci. Technol. Mysore, 48, 296 (2011).

2. J.R. Jeon, E.J. Kim, K. Murugesan, H.K. Park, Y.M. Kim, J.H. Kwon, W.G. Kim, J.Y. Lee and Y.S. Chang, Microb. Biotechnol., 3, 324 (2010).

3. B. Payet, A. Shum Cheong Sing and J. Smadja, J. Agric. Food Chem., 53, 10074 (2005).

4. J. Maurício Duarte-Almeida, A.V. Novoa, A.F. Linares, F.M. Lajolo and M. Inés Genovese, Plant Foods Hum. Nutr., 61, 187 (2006).

5. M.S.A. Moraes, F. Georges, S.R. Almeida, F.C. Damasceno, G.P.S. Maciel, C.A. Zini, R.A. Jacques and E.B. Caramão, Fuel Process. Technol., 101, 35 (2012).

6. F.Y. Chen, D.D. Jiang and Y.B. Tang, Appl. Mech. Mater., 253, 914 (2013).

7. J.M. Duarte-Almeida, A. Salatino, M.I. Genovese and F.M. Lajolo, Food Chem., 125, 660 (2011).

8. J.P. Anjos, M.G. Cardoso, A.A. Saczk, H.S. Dórea, W.D. Santiago, A.M.R. Machado, L.M. Zacaroni and D.L. Nelson, J. Braz. Chem. Soc., 22, 1307 (2011).

9. A. Caro and A. Piga, Eur. Food Res. Technol., 226, 715 (2008). 